\title{
The activities and impact of Personalisation in a UK Business School
}

Adam Jones, Baback Yazdani and Harry Barton

Nottingham Business School, Nottingham Trent University, Nottingham, UK

\begin{abstract}
The aim of this study is to consider the activities and impact of Personalisation in a UK higher education setting. It will consider how personalisation has affected outputs in terms of progression, achievement, internship, enterprise project and international placement uptake within the Nottingham Business School at Nottingham Trent University.

The Methodology comprised of using qualitative and quantitative data. Semi-structured interviews were carried out with members of the Personalisation team and those in the delivery of Personalisation. The quantitative data pertains to outputs in terms of success rates, particularly with regard to when the Personalisation project began in 2015/16.
\end{abstract}

The findings suggest that the Personalisation process involves engagement, interaction and reflection to meet the needs and requirements of the learner, as well as providing them options. This contributes to success rates with the outputs, particularly when the Personalisation project began.

\section{Keywords}

Personalisation, activities, impact, success rates, business education.

\section{Introduction}

This study will consider the activities of personalisation and how personalisation has affected business and management education within the Nottingham Business School at Nottingham Trent University. It will consider in particular the activities of personalisation within the learning dimensions: Knowledge, Learning Styles, Experiential Learning and Career. This will consider improvements to personalisation. It will also consider impact of personalisation on undergraduates in terms of outputs. The outputs will be progression rates, those achieving a 'good degree', the uptake of internships, enterprise projects and international placements.

A review of Personalisation will be provided, which will start with a definition of Personalisation and how it originated. The definition considers the needs of the learner, and how they can choose and receive their own personalised services. The key theory that underpins personalisation will be explored which is Vygotsky's Zone of Proximal Development (1978) based upon social constructivism. This includes social interactions as key to learning. It will also include propositions related to this theory. The way in which Personalisation formed from the independent living movement and personalised public sector services will also be considered. The requirement for personalised learning will be provided, as well as the benefits and drawbacks of Personalisation. The review also found that the use of Personal Learning Environments (PLEs) were a key method for personalising learning, and this is supported through the incorporation of Information and Communications Technologies (ICTs). Personalised learning has evolved through the use of PLEs 
which comprise ICTs. The PLEs are flexible in that they can depend upon the learner's preferences and are formed from this. In order to enhance this learning experience, it is important to understand the learner's previous history, motivations and desires.

A unique personalised learning chart will be produced to illustrate the personalisation process from the review. A key component of this chart is the interaction between the learner's and the facilitator, as well as various factors that are important in enhancing the personalisation experience (e.g. feedback, individual learning styles, resources, the community and the department). With this own personalised learning chart there is flexibility for the learner in that the learning process can be amended and evolve through the learning experience. It is about the support involved in enhancing the personalised learning experience and achieving successful learning outcomes for the learner. It is important to provide the learner and the facilitator with appropriate guidance to enable a personalised learning experience.

The methodology will consist of carrying out qualitative interviews with members of the personalisation team. The qualitative data will consist of the personalisation activities which take place within the learning dimensions: Knowledge, Learning Styles, Experiential Learning and Career. The quantitative data will consist of outputs in terms of progression rates, those achieving 'good degrees', the take up of internships, enterprise projects and international placements. The data will be analysed and presented. The outputs will be considered in particular when the personalisation project began in 2015/16.

A conclusion of the findings from the study will be provided, as well as recommendations to improve personalisation for learners to ensure successful learning.

\section{Synthesis of literature}

It has been found from a review of the literature that definitions of Personalisation focus upon the needs of the individual learner and allow them to choose their own services and how they are delivered. (BVSC 2010, Personalised Learning A Policy Overview 2016, pp. 5, Yazdani 2016). The services are therefore delivered to the needs and requirements of the individual learners.

Personalisation has been described as "developing a joint understanding and a specific agreed plan, between the student and the school for each student's needs with respect to their study pathway within the overall limits of their course, their experiential learning pathway and their learning approach in order to enhance their success potential in their studies and future career" (Yazdani 2016).

\section{The origins of personalisation}

The origins of personalisation are in the independent living movement and social model of disability (BVSC 2010 and Williams 1983, pp. 1003). The social model of disability and independent living movement originated from the campus culture of American universities in the 1970s and rehabilitation. The Rehabilitation Act of 1973 was created to "provide independent living services for whom vocational training was not a realistic option", and was also centred around those who were considered to have a disability. As a result, programmes were created to help sustain this independent movement. The providing of personalised services to individuals was initially used in public service delivery. Therefore, Personalisation as an educational policy was introduced as a wider idea for public services (Campbell et al 2007, pp. 135 and Mincu 2012, pp. 5). Personalisation in education was therefore as a result of public service personalisation, and meeting individual needs and requirements. 


\section{The theory of personalisation}

The key theory that underpins Personalisation is Vygotsky's Zone of Proximal Development (1978). This is based upon the social constructivism theory whereby knowledge is constructed by learners (Doolittle 1997, pp. 83-92 and Kiraly 2014, pp. 1). It is based upon using socially relevant tools and culturally based signs through interactions with other students and adults (Doolittle 1997, pp. 84). The Zone of Proximal Development considers that early on in the learning process the student requires more assistance whereas later on they require less assistance (Doolittle 1995, pp. 85). Its propositions include positive interdependence (the requirement for group cooperation to achieve goals), face to face interaction (encouraging and facilitating other group members), individual accountability (each student completing their task), small group and interpersonal skills (performing competently with others) and group self-evaluation (monitoring current instruction) (Doolittle 1997, pp. 83-92). To reiterate this, it was found that learning gains occurred when teachers extended their traditional views of teaching and learning from instruction to knowledge construction (Apple Computer 1995 cited in Mincu 2012, pp. 8). The social interactions are considered necessary for a successful personalised learning experience.

\section{Meeting the needs and requirements of the learner}

Since the $20^{\text {th }}$ century there has been a one size fits all approach to education, with little recognition of individuality, personal needs or aspirations. However, since the $21^{\text {st }}$ century, systems have been developed to individual needs. In education this is about meeting the needs of every learner (Personalised Learning A Policy Overview 2016, pp. 5). While some of the benefits to personalisation include enhanced student motivation, satisfaction, achievement and career progression, some of the challenges included students that were not interested in forming relationships with staff and were considered as consumers. There was also the scale and diversity of the cohort as well as centralised systems in place which reduce interactions between staff and students and resource constraints (Becket and Brookes 2012, pp. 26).

It is important therefore to meet the learner's individual needs and requirements. It was found that the learning environment can influence the motivation and success of graduates and in particular the peer interaction that comprises it (Leidenfrost et al 2011, pp. 347 and Vermeulen and Schmidt 2008, pp. 442), as well as the student teacher relationship and extra curricula activities (Vermeulen and Schmidt 2008, pp. 431).

\section{Personal Learning Environments (PLEs)}

PLEs have contributed to a personalised learning experience for the learner with regards to selfregulated learning. A PLE can consist of learning objects, suitable teaching and learning methods and activities which correspond to the learner's preferred learning style (Kurilovas et al 2014, pp. 654). It is important to teach students to become self-regulated learners for creating, managing and sustaining PLEs, and that goal setting, time management and task strategies are important in selfregulated learning in order to organise a PLE (Dabbagh and Kitsantas 2011, pp. 7, Yen et al 2013, pp. 46). However, not all students possess the knowledge management and self-regulatory skills to customise PLEs to provide their own learning experience (Dabbagh and Kitsantas 2011, pp. 3). This is something that should be addressed in order to provide a successful learning experience through the use of PLEs. The use of PLEs can be supported through the use of ICTs. It was found that a personalised learning environment should be based upon the use of ICTs in order to ensure successful knowledge and the creation of knowledge (Ferrer 2012, pp. 109 and Rensfeldt 2012, pp. 406). PLEs are different to virtual learning environments in that they support personalised learning 
for individuals and groups (Melzer and Schoop 2015, pp. 2). The PLE should understand the individual learner so that future learning opportunities consider the learner's previous history and desires (Johnson and Liber 2008, pp. 6 and O'Donnell et al 2014, pp. 774). The learning content may differ dependent upon the learner's knowledge (O'Donnell et al 2014, pp. 745).

\section{Personalised learning chart}

From surveying the authors in the field of personalisation, an own personalised chart has been produced which shows how learners engage with the personalisation process. This is as shown:

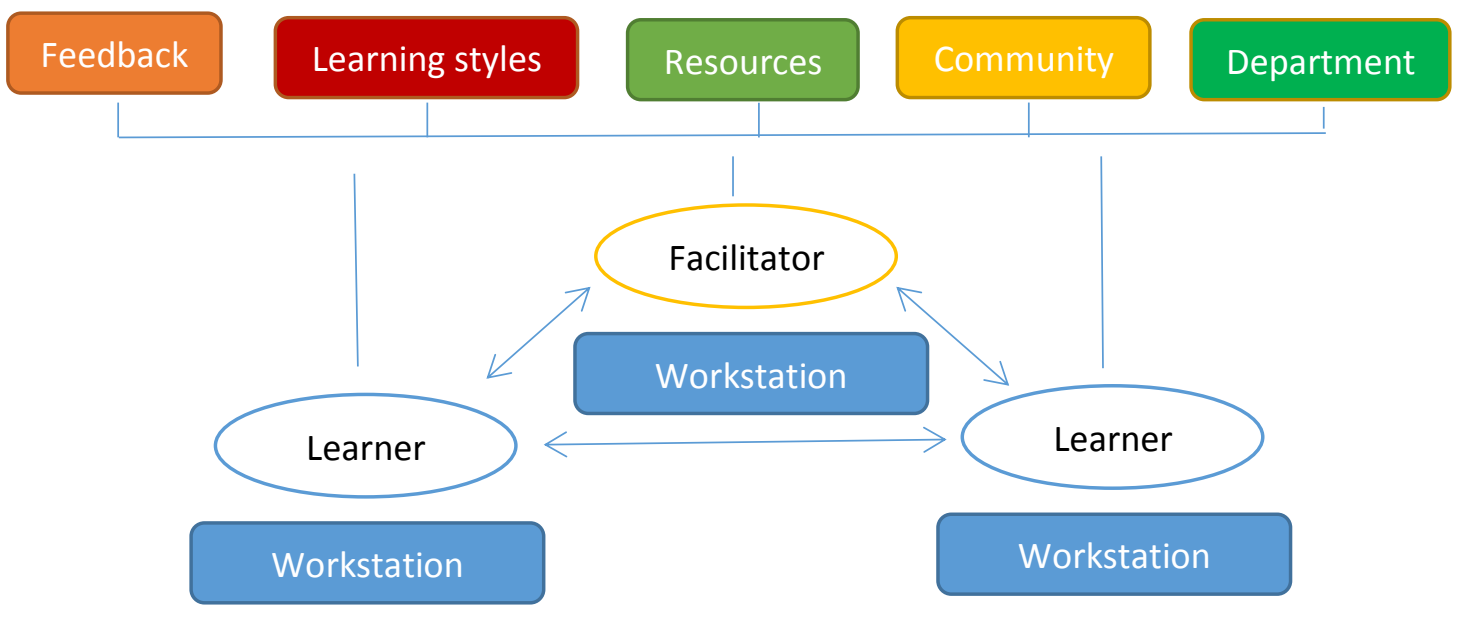

Figure 1: A chart to show key aspects of the Personalisation process which has been a result of the literature surveyed

To describe this chart a number of factors will determine the personalisation experience of the learner. The interactions between the learner's and the facilitator are key to a successful personalised learning experience. This interaction may be enhanced by technologically based mobile workstations. These may also allow the learner to create their own PLE. It is also important to consider mentoring styles in relation to an individual learner's style and understand their motivations, goals and desires. The facilitator's role should be more about guiding the learner's through the learning process and providing them support where necessary. A personalised learning experience will depend upon gaining knowledge and previous history of the individual learner, and this may be assessed by the facilitator. The facilitator and the learner's consider drawing upon support from the wider community, liaising closely with the department in terms of goal setting, drawing upon appropriate resources e.g. using socially relevant tools and culturally based signs, considering the learning styles of the learner and mentor, and receiving appropriate feedback. It is about understanding and meeting the requirements of individual learners, while also considering the interactions that take place. The facilitator will need to work collaboratively with the learners in order to understand them. This may also involve assessments to gain understanding on individual learning styles, as well as to establish what resources are available and preferred by the learner to enhance the personalised learning experience. This can be enhanced through the use of ICTs which have enabled personal learning environments to evolve. The use of ICTs helps to enable the creation of PLEs. These can allow further collaborative interactions to take place and possibly entertaining 
ways to learn. This personalised learning chart allows for flexibility in that the learning process can amend and evolve for the learner. The most important thing is for the learner and facilitator to integrate themselves into the learning experience and engage with the opportunities available.

To conclude, personalised learning is based upon the constructivism theory and Vygotsky's Zone of Proximal Development which focuses upon assistance, support and social interactions. It is based upon cooperative learning by the learners. There is a requirement for providing individuals with a personalised learning experience. A personalised learning experience depends upon a number of factors including the availability of resources, an understanding of the individual learner's requirements, their learning styles and an understanding of what is to be achieved. The learning environment is particularly important in contributing to a successful personalised learning experience. PLEs are considered a key component of personalised learning, and may consist and be supported through the use of ICTs. They allow the learner to create their own personalised learning environments. However, it is important to teach students to become self-regulated learners, in order to create and manage their own PLE. PLEs are flexible in that they can make use of activities which draw upon the learner's preferences. An own personalised learning chart has been produced to diagrammatically represent the processes involved in personalised learning. Peer based learning, guided by the facilitator is key to personalised learning, as well as allowing the learner to draw upon wider elements and utilise resources to enhance their learning experience. Personalisation is designed to be flexible for the learner, which will allow them to explore what is effective, and how the learning process can be amended to achieve the appropriate learning outcomes. It is important that the learner is aware of the learning opportunities available to them. A personalised learning experience will depend upon understanding between the individual and the facilitator, and make appropriate use of the learning opportunities available.

\section{Methodology}

In order to understand the activities of personalisation and what personalisation entails for students, the study will make use of qualitative interviews to be carried out with members of the personalisation team as well as those who were part of the delivery of it within the Nottingham Business School at Nottingham Trent University. The four key areas of the personalised learning experience include: Knowledge, Learning Styles, Career Support and Experiential Learning. It is important to establish what in particular students receive in terms of personalisation, and how this personalisation is delivered.

The impact and overall performance of personalisation on students is to be explored in order to establish whether there are positive outcomes e.g. in terms of progression and uptake of opportunities since the personalisation began. This will be achieved by interpreting quantitative data on progression rates, those achieving a 'good degree', internship uptake, enterprise project uptake and the uptake of international placements. The trends can also be considered. It is therefore important to consider whether student outcomes have improved as a result of personalisation. This is especially with regard to when the personalisation project began in 2015/16. There may be improvements to personalisation in order to improve success rates and outcomes. This can be determined from the activities and overall performance of personalisation. The data pertaining to internship uptake, enterprise project uptake and international placement uptake is related more to the experiential learning dimension of the personalisation process and can be used to consider success.

The methodology will therefore make use of qualitative and quantitative data to be interpreted. The data has been selected because it is relatively recent, and enables comparisons to be made in 
relation to when the personalisation project began. In order to understand more about personalisation, three members of the personalisation team were interviewed as well as two members who were involved in the delivery of personalisation.

\section{Results}

The activities of personalisation will be considered in accordance to the learning dimensions: Knowledge, Learning Styles, Experiential Learning and Career. The data has been interpreted and has been presented within these learning dimensions.

\section{Knowledge}

The team delivers two compulsory non-credit bearing modules: Personal and Professional Development (PPD) 1 and 2 which are run at levels 1 and 2 . There is a good take up and engagement with the modules. The personalisation team manage the modules, whereas the academic mentors work on and deliver the modules. While it is a pick and mix course, the optionality in terms of selecting modules is limited. There is no choice to select modules in the first year, and there is just one option slot to select a module in Levels 2 and 3 . The first years did not have lectures whereas the second years had lectures but not seminars. This enabled more free space.

The students are offered an academic mentor to provide support and encouragement to the student to enable them to be the best they can be. This can consist of one mentor with a group or one to one. There is concern for those who do not engage with the academic mentor. It is important to keep the student on track, motivate and guide them to Continual Professional Development (CPD) activities. The knowledge is produced from a reflective portfolio as part of these modules, and academic mentors are available to provide one to one personalised support and advice. This one to one mentoring can take place in the link lounge and group seminars. The meetings are flexible. There is initial contact and then the students are invited to attend the meetings to establish interactions and engagement. As well as meetings, discussions can take place through the telephone too. There are also students who are mentors and peers, as it is effective to listen to peers who had completed the course. The final year students also provide mentoring to first year students, and it is important to group interests. However, there is also emphasis placed on own development and support. There are learning set meetings which occur every term. The learning set meetings provide students with practical assistance and support.

It was found that students preferred an academic mentor and had different views on the meaning of personalisation. There is a better way to express it externally and it provides a brochure of opportunities. It is also about achieving recognition. Variety does not mean personalisation. Personalisation is also about practice based learning. The students understanding of personalisation was on choosing and selecting preferred modules. Personalisation is about identifying improvements and providing support by understanding the needs and requirements. It is about choice and the choice students are provided, as well as guidance to develop personally and professionally.

There is a requirement for students to receive 20 hours of CPD. The CPD is connected to the course. This occurs in the $2^{\text {nd }}$ and $3^{\text {rd }}$ year. However, there are optional events for CPD. The CPD also comprises study skills, employability, personal development and other to provide support. With CPD there is a reflective essay assignment, the monitoring of academic progress and how the students settled into University. The academic mentors can also provide support with this transition process of settling into University. As part of this, there are a series of activities, one to one mentoring and small and large groups involving activities. There is colour coding on the types of activities. There are different activities for different groupings of students. Characteristics are identified in each group 
and activities are provided in relation to this. The mentor is a guide to fill gaps to be addressed e.g. data or presentations. It provides an opportunity to reflect on activities, how to improve as well as the next objectives.

It was found that good students do better, whereas poor students do not achieve as well.

Personalisation benefits people who were already quite successful. It is about reaching students who require support, and how to reach the students who do not engage as much. The early engagement with students is important. There are seminar groups in which students are guided through the modules.

The personalisation project is more than just modules. The new NBS approach enables a personalised experience. This takes place within the modules. It is about the total student experience. The course is a collection of modes, assessments, mechanisms and delivery approaches. This is not the same however in saying it is personalised. The only choice is around the option module. In course activity is embedded within the modules which is more project based. A course is accredited by the Chartered Institute of Marketing. Personalised learning also involves extension tasks which is standard throughout the school.

The outputs to personalisation are in terms of satisfaction and attainment. Students who require additional support are signposted. To achieve this it is important to connect the activities and workshops.

\section{Learning Styles}

Learning styles are taught, as well as being directed to the library. Academic skills are developed through the library although everything is personalised. Diagnostic tests are available that enable students to choose from a wide range of tests, which also enables linkages to learning styles. Library workshops are provided which work with support services to support learning styles. The learning styles should also be linked to the experiential learning elements.

It was found that there is more work to do in terms of learning and teaching assessment, which is linked to learning styles. In order to meet the needs of learner's, it is about considering a diverse range of learning and teaching opportunities. The mentor is available at the workshops, and students found them to be helpful and positive. The learning styles should also consider the experiential learning that takes place. The learning and teaching styles also contribute towards engagement, as well as teaching and learning assessment. There is scope to consider improvements. For a particular course there is an online resource called My Accounting Lab which is used in addition to lectures and seminars. Students can work through this at their own pace. The structure of teaching fits in with components of the My Accounting Lab resource.

There is also more work to do in reaching the overall population of students, and early engagement is particularly important. Usage of technology is particularly important here, with there being less lectures. There is a student dashboard which is available that provides analytics in terms of the level of engagement e.g. low, partial, good and high engagement. It was found that attainment is increased at the higher end of engagement. In order to get students back on course, workshops are available to attend. From partial to good engagement there is a better rate of progression. Engagement is more effective for better engaged students, but not so well for those less engaged.

\section{Experiential Learning}

The experiential learning element is supported through the use of presentations in which interactions can take place. In Level 2 there is an experience opportunity e.g. study abroad, 
enterprise opportunity or community project. It is also when the student does a placement, internship, summer school, volunteering or other events they would like to attend. There was also a scheme to study at partner organisations as well as a summer school opportunity. These were found to be positive experiences. There are also workshops and inspirational events which students can attend. There are conference presentations and display boards which are used, as well as social connectedness. These include external speakers, presentation workshops, growth mind sets and google garages which are optional. In order to support well being, a half group event is available where discussions can take place.

It is important to reflect on the experiences and be aware of opportunities. The mission of the school is about experiencing and reflecting. This was personalised and was a success. They are also encouraged to attend the events. The experiential learning events should also be linked to learning styles.

The courses are either Sandwich or Full Time. There are also in company courses. With Sandwich course students, support is provided when applying to placements. The characteristics of Sandwich students are different to Full Time students. There are broad choices in terms of the architecture of the course, although there are limited options when compared to other schools.

The course leaders are set objectives to arrange activities e.g. sustainability, guest lectures, workshops, library services and student support to meet the student's needs and requirements. It is also about making aware of opportunities that may be considered to be beneficial. The students are encouraged to choose other activities e.g. volunteering to provide an enriching experience to develop confidence. The induction process could also be improved.

The course team delivers a research based activities project called NBS Discover which is about reimagining retail in Nottingham. A display board is provided to illustrate what has been achieved. The students can express their learning and present their work through power point, collages, space and the display board. There is good engagement as they work with each other and are familiar with the processes. A familiar topic helps with this.

\section{Career}

For career support, the employability team are consulted to identify individual needs and requirements. There is also a requirement to receive individual career advice. It is about working with employability to consider activities e.g. placements. The personalisation provided enables choice. There is also guidance to develop personally and professionally which helps students with their future career.

With the Personal and Professional 2 module, there is an understanding of the placements on offer, and help and guidance is provided to help the students prepare. In order to help with this process, it is about establishing interaction with the students in order to understand their needs and recommend a meeting with employability services. This interaction can take place at workshops. There is emphasis that is placed upon the placements. The personalised support provided discourages students going from Sandwich to Full Time courses. In order to help with career progression, some courses are accredited by the Chartered Institute of Marketing. There is a choice between the Chartered Institute of Marketing and google certificates. If the students do not take up the Chartered Institute of Marketing accreditation, they can choose google certificates for accreditation. This helps enable course accreditation when applying for jobs in the final year, and to help with their future career. 
In order to help with career, course leaders are set objectives in terms of arranging activities. These activities may relate to employability e.g. Future Hub. An objective in the course leader's appraisal is to identify CPD opportunities and promote and encourage students to engage with them. It is about channelling activity within the school for students and making them aware of the opportunities available. It is also about considering how business education and research impacts on business and society. The school has links with industry.

A table to represent the activities involved in personalisation is as shown:

\begin{tabular}{|c|c|c|c|}
\hline Knowledge & Learning Styles & $\begin{array}{l}\text { Experiential } \\
\text { Learning }\end{array}$ & Career \\
\hline PPD 1 and 2 modules & $\begin{array}{l}\text { Taught through } \\
\text { lectures }\end{array}$ & Presentations & $\begin{array}{l}\text { Employability team } \\
\text { providing career } \\
\text { advice }\end{array}$ \\
\hline Academic mentors & $\begin{array}{l}\text { Directed to } \\
\text { library }\end{array}$ & $\begin{array}{l}\text { Experience } \\
\text { opportunity in } \\
\text { level } 2\end{array}$ & Placement guidance \\
\hline $\begin{array}{l}\text { Option slot in levels } 2 \\
\text { and } 3\end{array}$ & Diagnostic tests & Activities & $\begin{array}{l}\text { Guidance to develop } \\
\text { personally and } \\
\text { professionally }\end{array}$ \\
\hline CPD activity & $\begin{array}{l}\text { Library } \\
\text { workshops }\end{array}$ & Guest lectures & PPD 2 module \\
\hline Seminar groups & Support services & $\begin{array}{l}\text { Reflect on } \\
\text { experience }\end{array}$ & Interaction \\
\hline Reflective portfolio & Mentors & $\begin{array}{l}\text { Sandwich or Full } \\
\text { Time courses }\end{array}$ & Workshops \\
\hline Practice based learning & Technology & $\begin{array}{l}\text { Conference } \\
\text { presentations }\end{array}$ & Course accreditation \\
\hline Learning set meetings & $\begin{array}{l}\text { Learning and } \\
\text { teaching } \\
\text { assessment }\end{array}$ & Display boards & Course activities \\
\hline Group activities & $\begin{array}{l}\text { Diverse teaching } \\
\text { and learning }\end{array}$ & $\begin{array}{l}\text { Wellbeing } \\
\text { support }\end{array}$ & $\begin{array}{l}\text { Course leader to } \\
\text { identify CPD } \\
\text { opportunities and } \\
\text { promote and } \\
\text { encourage }\end{array}$ \\
\hline Peer support & Workshops & $\begin{array}{l}\text { Research based } \\
\text { activities project }\end{array}$ & Channelling activity \\
\hline Engagement & & Workshops & Opportunities \\
\hline $\begin{array}{l}\text { In course project based } \\
\text { activity within modules }\end{array}$ & & & Future Hub \\
\hline
\end{tabular}

Table 1: A table to show the activities involved in personalisation 


\section{Outputs}

The outputs will consider progression from years 1 to 2 and years 2 to 3 and years 3 (or placement) to years 4 from the years $2011 / 12$ to $2015 / 16$. The data also considers the final year achievement for those who undertake Full Time and Sandwich courses from 2011/12 to 2015/16. The results also consider the uptake of internships from $2014 / 15$ to $2016 / 17$. The personalisation project was in 2015/16, so this should be considered in relation to this.

\section{Progression}

The progression from years 1 to 2 , year 2 to 3 and year 3 (placement) to year 4 from 2011/12 to 2015/16 is as shown below:

\begin{tabular}{|c|c|c|c|c|c|c|c|c|c|c|c|}
\hline & & & $/ 12$ & & $/ 13$ & & $/ 14$ & & & & \\
\hline \multicolumn{2}{|c|}{ Student Progression } & No & $\%$ & No & $\%$ & No & $\%$ & No & $\%$ & No & $\%$ \\
\hline \multirow{3}{*}{ Total } & Year 1 to Year 2 & 829 & $87 \%$ & 702 & $79 \%$ & 848 & $85 \%$ & 1018 & $84 \%$ & 989 & $80 \%$ \\
\hline & Year 2 to Year 3 & 987 & $86 \%$ & 890 & $84 \%$ & 777 & $87 \%$ & 832 & $88 \%$ & 1041 & $90 \%$ \\
\hline & Year 3 (Placement) to Year 4 & 412 & $99 \%$ & 282 & $98 \%$ & 284 & $99 \%$ & 237 & $99 \%$ & 353 & $\mathbf{9 9 \%}$ \\
\hline
\end{tabular}

Table 2: A table to show progression rates from 2011/12 to 2015/16

This is represented in the graph as shown:

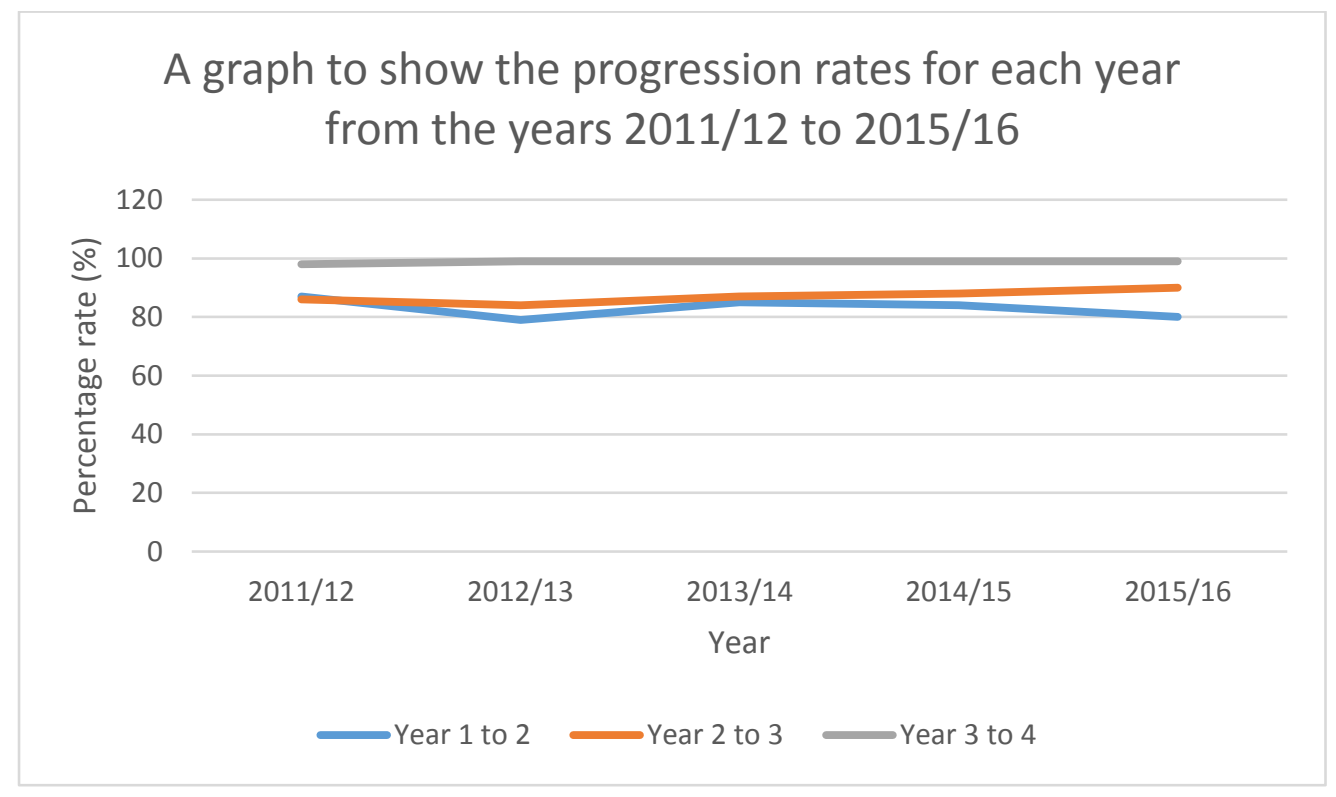

Figure 2: A graph to show the progression rates for each year from the years $2011 / 12$ to $2015 / 16$

From the results it was found that the progression rate between years 3 (placement) to 4 was greater than years 1 to 2 and years 2 to 3 for all academic years. The progression rates for years 3 to 4 was also consistent. The progression rate between years 2 and 3 was greater than years 1 to 2 for all academic years apart from one year (2011/12). This shows that more should be understood and improvements made to increase progression from years 1 to 2 . In years 2 to 3 the progression is greatest for the most recent year (2015/16). This was also the year when the personalisation project began. In years 3 (placement) to 4 the progression remains consistent apart from one year 
(2012/13). Interestingly the greatest progression rates for years 2 to 3 and years 3 to 4 was in year 2015/16 (when the personalisation project began).

\section{Achievement}

Those achieving a 'good degree' from the years $2011 / 12$ to $2015 / 16$ is shown below:

\begin{tabular}{|c|c|c|c|c|c|c|c|c|c|c|}
\hline Undergraduate & \multicolumn{2}{|c|}{$2011 / 12$} & \multicolumn{2}{|c|}{$2012 / 13$} & \multicolumn{2}{|c|}{$2013 / 14$} & \multicolumn{2}{|c|}{$2014 / 15$} & \multicolumn{2}{|c|}{$2015 / 16$} \\
\hline Award & No & $\%$ & No & $\%$ & No & $\%$ & No & $\%$ & No & $\%$ \\
\hline Good Honours & & $55.5 \%$ & & $60.8 \%$ & & $62.1 \%$ & & $72.1 \%$ & & $68.2 \%$ \\
\hline Total & 1000 & & 1238 & & 964 & & 836 & & 750 & \\
\hline
\end{tabular}

Table 3: A table to show those achieving a 'good degree' from 2011/12 to 2015/16

This is represented as shown in the graph below:

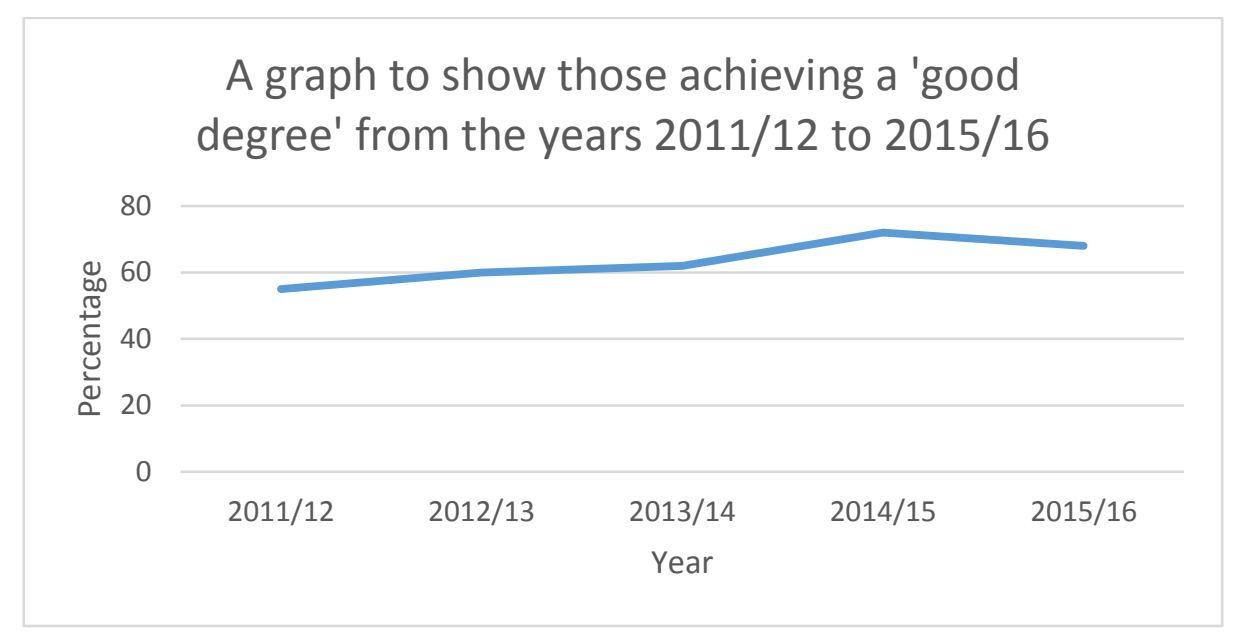

Figure 3: A graph to show those achieving a 'good degree' from the years 2011/12 to 2015/16

From this, it would seem that overall, those achieving a 'good degree' has increased. There was a slight decrease in the most recent year (2015/16). This shows an overall improvement in the success rates.

\section{Internship uptake}

In terms of the take up of year 2 opportunities, the following data represents the uptake of undergraduate internships from 2014/15 to 2016/17.

\begin{tabular}{|c|c|c|}
\hline $2014 / 15$ & $2015 / 16$ & $2016 / 17$ \\
\hline 23 & 38 & 24 \\
\hline
\end{tabular}

Table 4: A table to show the uptake of internships from $2014 / 15$ to $2016 / 17$

This can be represented in the following graph. 


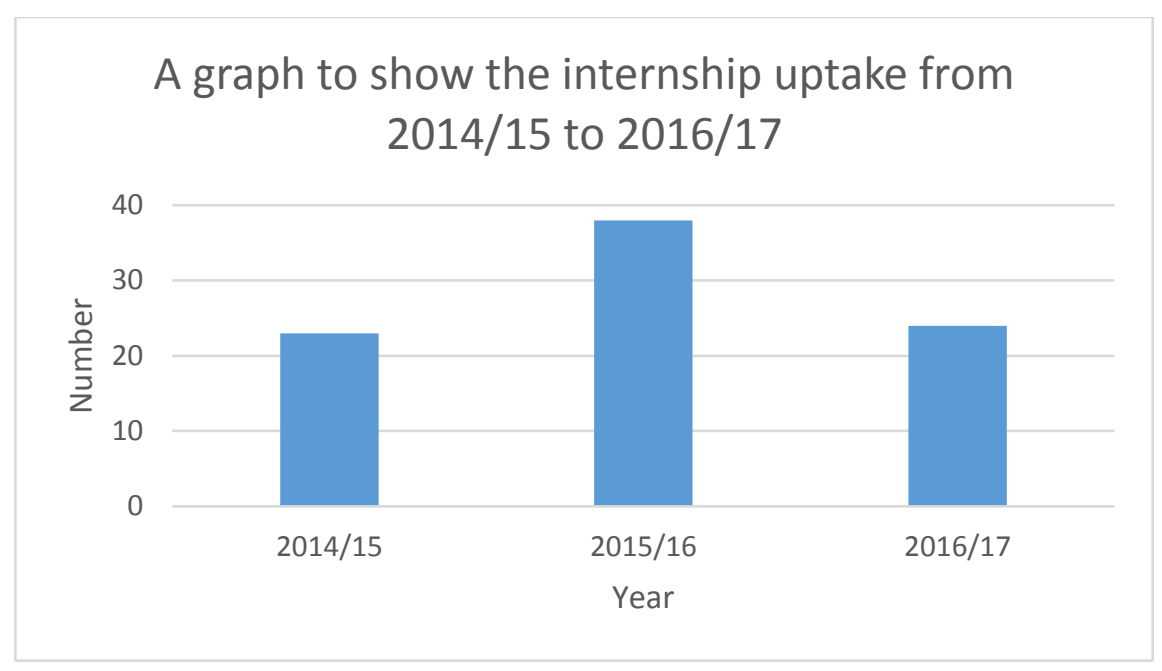

Figure 4: A graph to show the uptake of internships from 2014/15 to 2016/17

Interestingly, the greatest uptake of internships occurred in 2015/16. This was the year that the personalisation project began. The personalisation project could therefore contribute to this greater uptake of internships. However, there was a slight decrease in the most recent year (2016/17).

\section{Enterprise project uptake}

The enterprise project results are as shown:

\begin{tabular}{|c|c|c|c|c|}
\hline $2011 / 12$ & $2012 / 13$ & $2013 / 14$ & $2014 / 15$ & $2015 / 16$ \\
\hline 5 & 1 & 7 & 8 & 17 \\
\hline
\end{tabular}

Table 5: A table to show the uptake of enterprise projects from 2011/12 to 2015/16 This is represented in the following graph.

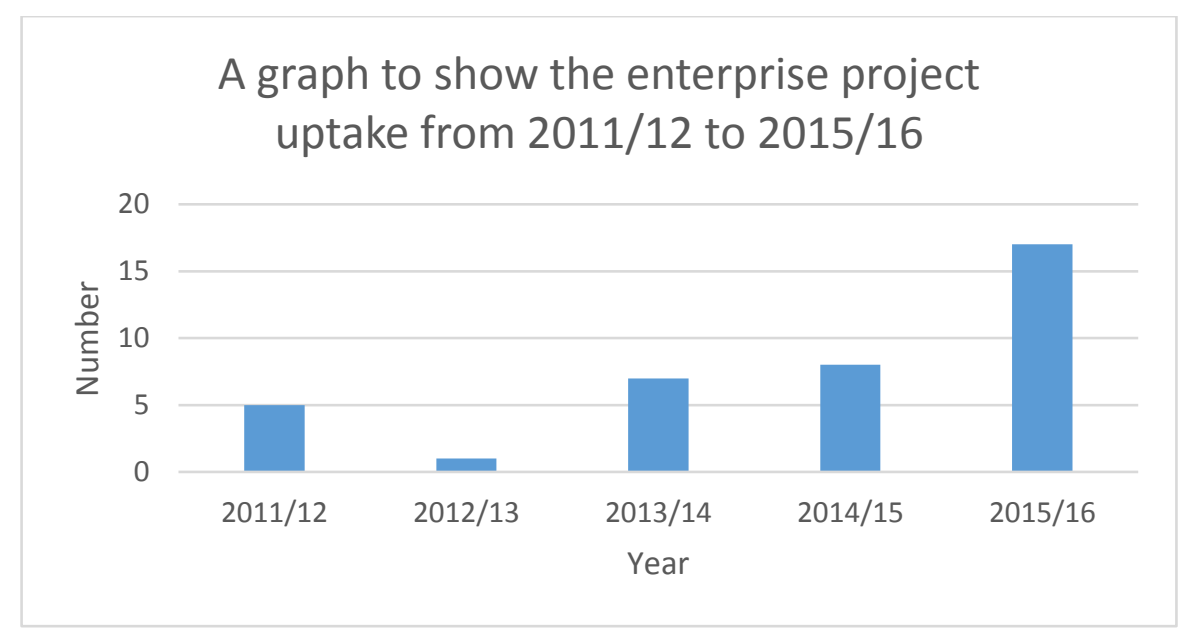

Figure 5: A graph to show the uptake of enterprise projects from 2011/12 to 2015/16

The results suggest that enterprise projects have overall increased, and in particular from 2012/13. The largest increase is in $2015 / 16$ when the personalisation project began. This may suggest that the personalisation project could influence this increase in the enterprise project uptake. 


\section{International placements}

The results for international placements half year 2 from 2011/12 to 2016/17 are as shown:

\begin{tabular}{|c|c|c|c|c|c|}
\hline $2011 / 12$ & $2012 / 13$ & $2013 / 14$ & $2014 / 15$ & $2015 / 16$ & $2016 / 17$ \\
\hline 13 & 12 & 6 & 11 & 7 & 14 \\
\hline
\end{tabular}

Table 6: A table to show the uptake of international placements from 2011/12 to 2016/17

This is shown in the graph below:

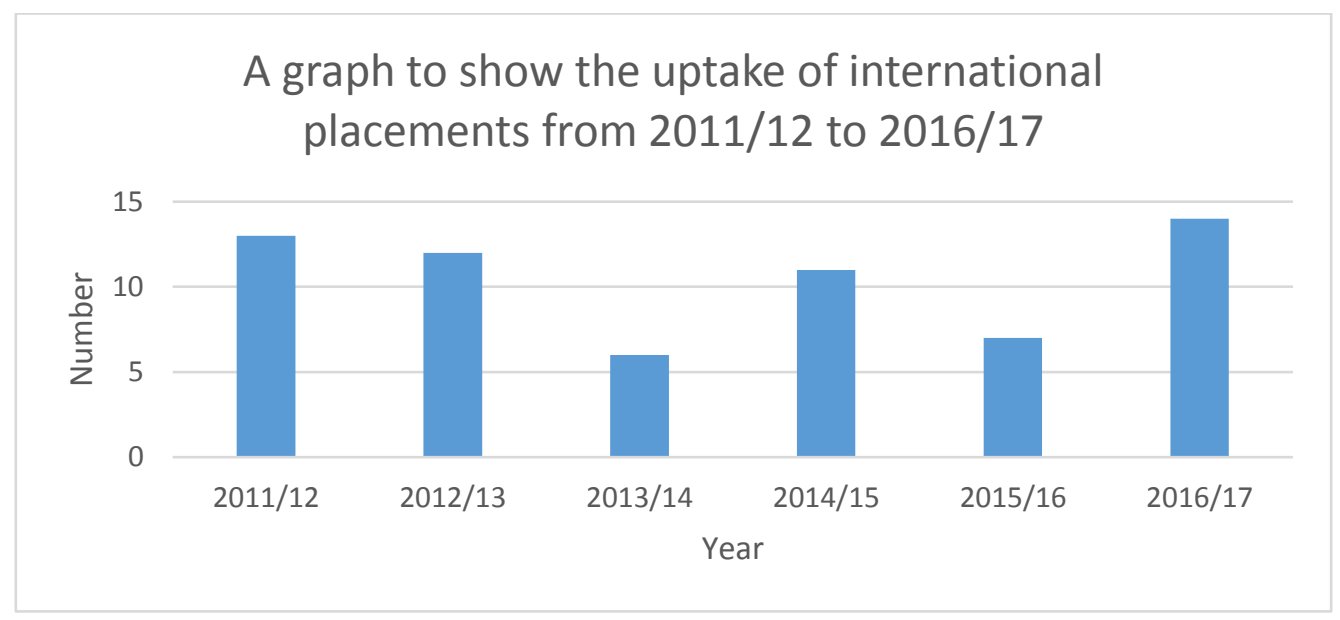

Figure 6: A graph to show the uptake of international placements from 2011/12 to 2016/17

Interestingly the uptake of international placements has decreased from 2011/12 to 2013/14. There was a slight increase in 2014/15 and then a decrease in 2015/16. However, the largest increase was in 2016/17, which was after the personalisation project began in 2015/16.

Overall it would seem that there are increases with progression rates, 'good degrees' and internship uptakes from 2011/12 to 2015/16. There are also increases with progression rates with enterprise projects from $2013 / 14$ to $2015 / 16$. There were increases in the uptake of international placements from $2015 / 16$ to $2016 / 17$.

\section{Conclusion}

To conclude, the personalisation process involves engagement, interaction and reflection, and these factors may contribute to success rates, particularly from 2015/16 when the personalisation project began. With the outputs, it was found that with progression, a 'good degree', internships, enterprise projects and international placements, there were overall increases in success rates.

In order to further this interaction, there should be various methods of discussion. The discussions can take place with the mentors as part of the mentoring scheme. Project based activities which take place are also part of this interaction and engagement. It is also about utilising a diverse range of teaching and learning opportunities. The learning styles are taught at lectures, as well support provided through the library and support services. The experiential learning makes use of an experience opportunity, and activities are arranged to meet needs and requirements. The employability team provide career support and guidance, and activities are arranged in relation to this. 
The Personalisation activities that occur within the school are based upon Vygotsky's Zone of Proximal Development in which assistance, support and social interactions take place. This is based upon the constructivism theory in which interactions take place to increase knowledge. The Personalisation process also involves meeting the needs and requirements of the learner, as well as the options that are available. This focuses upon the definitions of Personalisation. The activities of Personalisation of interaction and reflection also follow Vygotsky's Zone of Proximal Development which entails group interaction and self-evaluation. In order to increase interactions between teachers and learners, seminars, learning set meetings, workshops and mentoring schemes have been put in place. There are also project based group activities which take place. The learning environment is influenced by interactions as well as extra curricula activities. The personalisation process entails mentoring and group activities which enable interactions. The extra curricula activities could be from volunteering. However, a consideration to improve personalisation could be to utilise further extra curricula activities. The activities of Personalisation also focus upon the learner's learning style, which is related to PLEs in terms of meeting the learner's learning style. The activities of Personalisation to increase knowledge also involve putting emphasis on own development. This is in relation to PLEs in which it is important to teach those to become selfregulated learners. A PLE is about understanding the learner in order to consider learning opportunities. This is similar to the Personalisation process which is about understanding the learner's needs and requirements. The own personalised chart reflects the activities of Personalisation in that collaboration and interaction occurs. It is also about utilising appropriate resources in the form of mentors and workshops, understanding learning styles, providing feedback, the community and the department. It is a collaborative process which involves various aspects of Personalisation. This follows the way Personalisation activities are carried out.

In terms of the activities of personalisation, there is an option to select a module in Levels 2 and 3. There is no option slot in Level 1 . The optionality in terms of selecting modules is therefore limited. The students who do not engage as much are limited in terms of the opportunities available which may influence success rates. This engagement is therefore important in success. It is important to reach out to the overall population of students for engagement. Engagement is more effective for better engaged students, but not so well for those less engaged. It is also about understanding the meaning of personalisation. Personalisation is about selecting modules, as well as meeting needs and requirements. It is also about the guidance and support that is provided to develop personally and professionally. A further understanding of learning and teaching assessment is required, and considering a diverse range of learning and teaching. The experience opportunities were found to be positive experiences. There was good engagement with the research based activities project in which students present and express their work. It was found that the induction process could be improved.

While the effects of personalisation can be represented by positive outcomes, particularly from 2015/16, the optionality may still be regarded as limited. Therefore, in order to improve personalisation, there could be more than one module option slot available in Levels 2 and 3. In order to enhance engagement, there should be encouragement, as well as making aware of the benefits of engaging with these opportunities. In order to achieve this, a number of methods could be used to increase awareness of these opportunities e.g. through mentoring, lectures and seminars and workshops. There should be contact made with those who are less engaged, and to highlight the opportunities available to them. It is also important to ensure that awareness is made with the guidance and support that is available. It is important to help educate the learners of the opportunities that are available to them, particularly with regards to the CPD activities that comprise personalisation as well as the available support. It is also important to educate the learners about 
the resources available to them and the activities that take place, to ensure successful learning. In order to meet the needs and requirements of the learner, the teaching should be adapted to consider learning styles. The learning and teaching assessment should also be understood, in order for effective learning to take place. This can make use of a diverse range of learning and teaching assessments to meet the learning styles of the learner. This may also take place in the form of seminars in which an understanding of the learning styles can be ascertained. Feedback may be important here between the teacher and learner. It would also be useful to understand how the induction process could be improved in order to meet the needs and requirements of the learner. In terms of outputs, it would also be important to understand why there is an overall increase in progression rates between years 3 (placement) and 4 than years 1 to 2 . This was consistent for all years apart from in 2011/12. The personalisation process may pertain more to certain years (e.g. years 3 (placement) and 4 ) than others.

Personalisation may have a positive effect on progression rates, those achieving a 'good degree', the take up of year 2 opportunities, internships, enterprise projects and international placements.

However, improvements may consider the optionality available in terms of selecting modules which may be limited in meeting needs and requirements of the learners. Some aspects of the personalisation process may be used more than others. The collaboration between learners and the teachers is also of importance, as it is important to establish dialogue to facilitate successful learning. It is important to enable flexibility for the learner particularly in terms of learning styles, while also meeting learning objectives. Other aspects of the personalisation process may also need to be considered. It is also important to consider the reasons for these positive effects on progression and uptake of opportunities, and how personalisation can be improved and what in particular makes the personalisation process successful.

\section{Funding}

The author(s) received no financial support for the research, authorship, and/or publication of this article.

\section{References}

Apple Computer (1995) Changing the conversation about teaching, learning \& technology. A report on 10 years of ACOT research. Cupertino, CA: Apple.

Becket $\mathrm{N}$ and Brookes $\mathrm{M}$ (2012) The potential benefits and challenges of personalising UK higher education. Journal of Hospitality, Leisure, Sport and Tourism Education, 11: 21-28.

BVCS (2010) The Origins of Personalisation. The Centre for Voluntary Action. Available at: https://www.bvsc.org/sites/default/files/privatefiles/Assembly\%20personalisation\%20presentation. pdf [Accessed 10 October 2016].

Campbell R, Robinson W, Neelands J, Hewston R and Mazzoli L (2007) Personalised learning: Ambiguities in theory and practice. British Journal of Educational Studies, 55(2): 135-154.

Dabagh N and Kitsantas A (2012) Personal Learning Environments, social media, and self-regulated learning: A natural formula for connecting formal and informal learning. Internet and Higher Education, 15: 3-8.

Doolittle P (1997) Vygotsky's Zone of Proximal Development as a Theoretical Foundation for Cooperative Learning. Journal of Excellence in College Training, 8(1): 83-103. 
Johnson M and Liber O (2008) The Personal Learning Environment and the Human Condition: from theory to teaching practice, Interactive Learning Environments, 16(1): 3-15.

Kurilovas E, Kubilinskiene S and Dagiene V (2014) Web 3.0 - Based personalisation of learning objects in virtual learning environments. Computers in Human Behavior, 30: 654-662.

Leidenfrost B, Strassnig B, Schabmann A, Spiel C and Carbon C (2011) Peer Mentoring Styles and Their Contribution to Academic Success Among Mentees: A Person-Oriented Study in Higher Education. Mentoring and Tutoring: Partnership in Learning, 19(3): 347-364.

Melzer P, and Schoop, M (2015) A Conceptual Framework for Task and Tool Personalisation in IS Education. A Framework for Personalised Learning in IS-Education. In: Thirty Sixth International Conference on Information Systems.

Mincu M (2012) Personalisation of Education in Contexts. Policy Critique and Theories of Personal Improvement. Comparative and International Education: A Diversity of Voices. Sense Publishers, 18.

O'Donnell E, Sharp M, Wade V and O'Donnell, L (2014) Personalised E-Learning: The Assessment of Students Prior Knowledge in Higher Education. School of Management. Dublin Institute of Technology.

Personalised Learning A Policy Overview. Space for Personalised Learning. Report. Available at: http://www.complexneeds.org.uk/modules/Module-3.2-Engaging-in-learning---keyapproaches/D/downloads/m10p020d/personalised learning policy overview 100409 web.pdf [Accessed 10 October 2016].

Rensfeldt A (2012) (Information) Technologies of the Self: personalisation as a new mode of subjectivism and knowledge production. Department of Education, Communication and Learning, University of Gothenburg, Sweden, 9(4): 406.

Williams G (1983) The Movement for Independent Living: An Evaluation and Critique. Journal of Social Science and Medicine, 17(15): 1003-1010.

Vermeulen L and Schmidt $H$ (2008) Learning environment, learning process, academic outcomes and career success of university graduates. Studies in Higher Education, 22(4): 431-451.

Yazdani B (2016). Leading the Way in Personalisation and Experiential Learning. Available at: https://charteredabs.org/leading-way-personalisation-experiential-learning/ [Accessed: 10 October 2016].

Yen C, Tu C, Sujo-Montes L, Armfield S, Chan J (2013). Learner Self-Regulation and Web 2.0 Tools Management in Personal Learning Environment. International Journal of Web-Based Learning and Teaching Technologies, 8(1): 46-65. 